\title{
Methods to Measure Socio-Economic Inequalities in Health for Indian Adolescents
}

\author{
Priyanka Parmar*1, Manu R. Mathur ${ }^{1}$, Georgios Tsakos ${ }^{2}$ and Richard G. Watt ${ }^{2}$
}

${ }^{1}$ Public Health Foundation of India, Gurgaon, India; ${ }^{2}$ University College London, London, United Kingdom

\section{Objective}

To identify and validate methods and scales measuring determinants of social inequalities in health in context to Indian adolescents

\section{Introduction}

Health inequalities are major global public health problem and varies within and between countries [1]. LMICs particularly India, are undergoing a phase of rapid economic development leading to an increase in informal settlements or urban slums [2]. These settlements exhibits extreme poverty and suffers from adverse health outcomes. The worst affected are the adolescents because it is a crucial and most vulnerable age when health behaviours and lifestyle choices are established which affects their current and future health [3]. The current health system in many of the developing countries are outdated and have either rudimentary health statistics or none. There is lack of standardized and reliable questionnaires to capture various behavioural aspects of subjective health of the population in India. Thus, we aim to identify various measures of determinants of social inequalities relevant to the Indian adolescent population context.

\section{Methods}

We adopted scales and questions from internationally validated questionnaires, and conducted reliability and validity tests through a cross sectional study on 1386 adolescents residing in diverse areas of residence (slums, middle class and resettlement colonies) and standardized them to be used on Indian adolescent population. Questionnaire included important determinants of health: degree of neighbourhood social capital, level of social support, health related behaviours, self-rated health and key socio-demographic of adolescents. The social capital scale was adapted from an adolescent social capital scale used by Gage et al (2005) [4] and showed a reasonable internal consistency $($ Cronbach's Alpha $=0.63)$ when tested on Indian adolescents. Social support scale was adapted from the adolescent social support scale developed by Seidman et al (1995) [5] and showed excellent internal consistency (Cronbach's Alpha = 0.86) when tested on study population. Questions on health related behaviours were taken from WHO HBSC survey which is a survey of school children undertaken periodically in more than 40 countries of the world [6].

\section{Results}

A social gradient in health inequalities was observed with a sequentially detrimental health outcome at each lower level of areas of residence.

\section{Conclusions}

The questionnaire was observed sensitive to LMICs setting and consistent with both international as well as Indian adolescents context. Studying both clinical and subjective health outcomes in a population can provide important insights about different explanations of various indicators of health, highlighting the complex nature of inequalities. The questionnaire is useful in identifying social inequalities in health to advance health equity among adolescents.

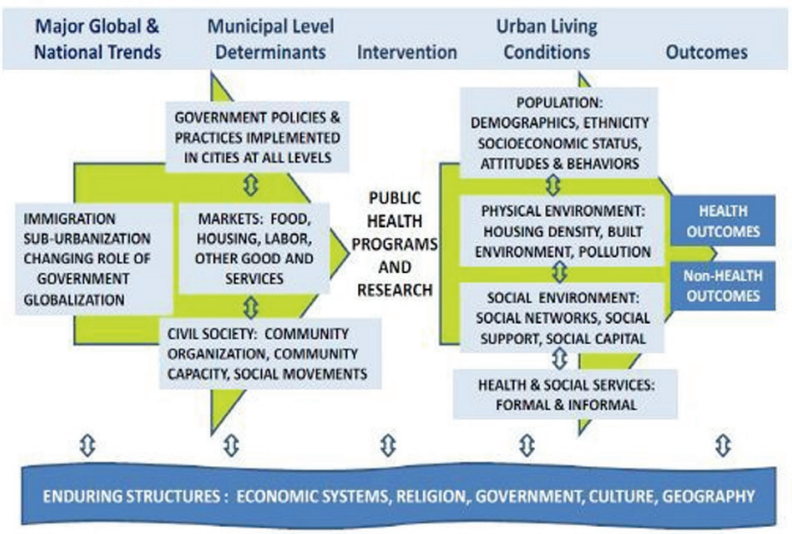

Conceptual Framework of Urban Health (Galea et al., 2005)

Keywords

Social Inequalities; Methods; Adolescents

\section{Acknowledgments}

This work was supported by a Wellcome Trust Capacity Strengthening Award to the Public Health Foundation of India and a consortium of UK universities.

\section{References}

1. Marmot M. Public Health Social determinants of health inequalities Lancet. 2005;365:1099-104

2. Vlahov D, Freudenberg N, Proietti F, Ompad D, Quinn A, Nandi V, et al. Urban as a determinant of health. J. Urban Heal. 2007;84.

3. Wiefferink CH, Peters L, Hoekstra F, Ten Dam G, Buijs GJ, Paulussen TGWM. Clustering of health-related behaviors and their determinants: Possible consequences for school health interventions. Prev. Sci. 2006. p. $127-49$.

4. Gage JC, Overpeck MD, Nansel TR, Kogan MD. Peer activity in the evenings and participation in aggressive and problem behaviors. J. Adolesc. Health. 2005;37:517.

5. Seidman E, Allen L, Lawrence Aber J, Mitchell C, Feinman J, Yoshikawa H, et al. Development and validation of adolescentperceived microsystem scales: Social support, daily hassles, and involvement. Am. J. Community Psychol. 1995;23:355-88.

6. Roberts C, Freeman J, Samdal O, Schnohr CW, de Looze ME, Nic Gabhainn S, et al. The Health Behaviour in School-aged Children (HBSC) study: methodological developments and current tensions. Int. J. Public Health. 2009;54 Suppl 2:140-50.

\section{*Priyanka Parmar}

E-mail: priyachoudhary22@hotmail.com 